Tohoku J. exp. Med., 1981, 135, 1-9

\title{
Follow-Up Studies of Surgical Treatment for Gholedocholithiasis
}

\author{
Toshio Sato, Noriyoshi Suzuki, Wataru Takahashi, \\ and Ikunoshin Uematsu \\ Department of Surgery, Tohoku University School of Medicine, \\ Sendai 980
}

Sato, T., Suzuki, N., Takahashi, W. and Ummatsu, I. Follow-Up Studies of Surgical Treatment for Choledocholithiasis. Tohoku J. exp. Med., 1981, 135 (1), 1-9 The follow-up results of cholecystectomy and common duct exploration with T-tube drainage for 308 patients with common bile duct stones were studied. Nine patients evaluated as "poor" included seven with residual stones and two with recurrent stones. Cholangiography at the time of follow-up manifested the evidence of a statistically significant reduction of the bile-duct diameter compared with the preoperative level in both cholesterol and calcium bilirubinate cases. The reduction was particularly conspicuous in the group with marked dilatation of the bile duct, regardless of the types of stone. Of the 134 patients with cholelithiasis who underwent reoperations in our Department, 75 $(87 \%)$ belonged to residual, $11(13 \%)$ to recurrent group. Of the 11 patients with recurrent stones, nine had obvious causes for stone recurrence such as bileduct stenosis or stricture at the anastomotic site. These results suggest that without existence of evident stenosis at the papilla of Vater or in the lower bile duct, patients with choledocholithiasis, regardless of types of stone, could be curable effectively only by cholecystectomy and choledocholithotomy with T-tube drainage. choledocholithiasis; transduodenal sphincteroplasty; calcium bilirubinate stone

Among many problems concerning the surgical treatment of cholelithiasis, determination of the indication for the drainage procedures is still of significant importance. Transduodenal sphincteroplasty (sphincteroplasty in general) proposed by Jones et al. $(1952,1963)$ is used still frequently as one of the drainage procedures. Sphincteroplasty is usually indicated for the patients with either gallstone or biliary debris which cannot be removed adequately, or with stenosis of the papilla of Vater. On the other hand, some reports (Ferris et al. 1964; Johnson and Rains 1978; Jones 1978; Mudden 1978) have emphasized that sphincteroplasty or bilioenteric anastomosis is a choice of operation if there exists a possibility of recurrence of stones. In this paper, in order to evaluate the necessity of drainage procedure for choledocholithiasis, patients who underwent cholecystectomy and choledocholithotomy with T-tube drainage and those with cholelithiasis subjected to reoperations were reviewed.

Received for publication, November 7, 1980. 


\section{Materials and Methods}

During the period between April 1961 and March 1979, a total of 1,474 patients with gallstone disease excluding those with malignant tumors of the hepato-biliary system were operated on at our Department. They consisted of 1,045 patients with cholecystolithiasis, 328 with choledocholithiasis, and 101 with intrahepatic gallstones. The gallstones were composed of choresterol in 1,036 cases, calcium bilirubinate stone in 305, pure pigment stone in 116, and others in 17. Follow-up studies were carried out in 308 patients who survived more than one year after cholecystectomy and common duct exploration with $\mathrm{T}$ tube drainage as the initial operation. Patients with intrahepatic gallstones were excluded. Gallstones were located in the gallbladder in 98, in common bile duct in 67 and in both in 143. The types of stone were cholesterol in 210 and calcium bilirubinate in 98 (Table 1). The patients with pure pigment stone and other stones were so small in number that they were excluded from the present study.

At the time of follow-up, patients were classified into four groups according to a diameter of the bile duct on the preoperative cholangiogram; normal diameter (less than $7 \mathrm{~mm}$ ), mild $(7-12 \mathrm{~mm})$, moderate $(13-20 \mathrm{~mm})$, and marked dilatation (21 $\mathrm{mm}$ or above). There was no instance of the bile duct with a diameter less than $7 \mathrm{~mm}$. Follow-up studies were also available in 134 patients who underwent reoperation in our clinic; most of them had received initial operations in other institutions.

TABLe 1. Patients with T-tube drainage

\begin{tabular}{lccc}
\hline \multirow{2}{*}{ Location of stone } & $\begin{array}{c}\text { Number } \\
\text { of } \\
\text { patients }\end{array}$ & \multicolumn{2}{c}{ Number of patients according to types of stone } \\
\cline { 3 - 4 } & Cholesterol stone & Calcium bilirubinate stone \\
\hline Gallbladder & 98 & 84 & 14 \\
Gallbladder and & 143 & 99 & 44 \\
bile duct & 67 & 27 & 40 \\
Bile duct & 308 & 210 & 98 \\
\hline Total & & & \\
\hline
\end{tabular}

\section{Results}

Follow-up results obtained from questionnaires. Questionnaires were answered by 238 patients $(77.6 \%) ; 72 \%$ of the patients with cholesterol stones and $88 \%$ with calcium bilirubinate stones. Items questioned were on the presence or absence of pain, fever and jaundice, change in food intake and body weight, etc. The status of the patients at the time of follow-up were classified into three grades according to our criteria; "good" for those who have almost no complaint interfering the daily life, and completely rehabilitated to the preoperative occupation; "fair" for those who need a rest several times a year due to slight abdominal pain, but feel the general condition better than the preoperative state; and "poor" for those with frequent abdominal pain, fever or jaundice and having difficulty to lead the normal lives. The average follow-up period was 7.4 years, ranging from one to 12 years. The number of death during the follow-up period was seven in the cholesterol group and eight in the calcium bilirubinate group. All of them died of cardiovascular lesions rather than the hepatobiliary disease.

Follow-up results of the remaining 223 patients were as follows. In a cholesterol group, 121 patients $(79.6 \%)$ belonged to "good", $19(12.5 \%)$ to 
TAвLE 2. Follow-up results of patients with T-tube drainage

\begin{tabular}{cccccc}
\hline & \multirow{2}{*}{$\begin{array}{c}\text { Number } \\
\text { of } \\
\text { patients }\end{array}$} & Good & Fair & Poor & Died \\
\cline { 3 - 6 } & 152 & $121(79.6)$ & $19(12.5)$ & $5(3.3)$ & $7(4.6)$ \\
\hline $\begin{array}{c}\text { Cholesterol stone cases } \\
\text { Calcium bilirubinate } \\
\text { stone cases }\end{array}$ & 86 & $59(68.6)$ & $15(17.4)$ & $4(4.7)$ & $8(9.3)$ \\
Total & 238 & $180(75.6)$ & $34(14.2)$ & $9(3.9)$ & $15(6.3)$ \\
\hline
\end{tabular}

Figures in parentheses show percentages.

"fair", and $5(3.3 \%)$ to "poor". In a calcium bilirubinate group, 59 patients $(68.6 \%)$ belonged to "good", $15(17.4 \%)$ to "fair", and $4(4.7 \%)$ to "poor" (Table 2). There was no statistically significant difference in the follow-up results between these two groups.

In 180 out of the 223 patients, radiological visualization of the common bile duct was possible prior to surgery. Of the 180 cases, $84 \%$ to $100 \%$ in each group belonged to "good" state at follow-up. When "fair" cases were included, $90 \%$ to $100 \%$ of the patients were judged to have relatively satisfactory results. The "poor" state was seen in four cholesterol cases with mild bile-duct dilatation, one cholesterol and two calcium bilirubinate cases with moderate dilatation, and two calcium bilirubinate cases with marked dilatation. There was no significant difference in the results which could be ascribed to either the degree of bile-duct dilatation or the types of gallstone.

Results of detailed examination at the follow-up. Detailed examination was possible in 100 out of 223 patients who had answered our questionnaires. Types of stone were cholesterol in 64 and calcium bilirubinate in 36 patients. These 100 patients consist $45 \%$ of the patients who had answered our questionnaires. The interval between operation and the follow-up examination in the hospital ranged from one to 17 years and averaged at 5.5 years for patients with cholesterol stone, and 8.5 years for those with calcium bilirubinate stone. The examinations undertaken were hematology, serum bilirubin, S-GOT, S-GPT, alkaline phosphatase (Al-p), colloid reaction, ICG retention rate $(15 \mathrm{~min})$, plasma protein, lipids and others, drip-infusion cholangiography and the measurement of body weight.

Regardless of the degree of bile-duct dilatation or the difference in types of gallstone, the incidence of anemia (erythrocyte count less than 3.5 million) was remarkably reduced in these patients. Anemia which was observed in $22.2 \%$ of the patients at the time of discharge, was found only in $2.3 \%$ of these at the time of follow-up. At the time of discharge and follow-up, $90 \%$ of the patients showed the level of serum bilirubin less than $1.0 \mathrm{mg} / 100 \mathrm{ml}$. As illustrated in Fig. 1, the level of Al-p more than 10 units was seen in $54(65.1 \%)$ of the 83 patients at the time of discharge but in only $14(16.9 \%)$ at follow-up with statistically significant difference between them $(p<0.001)$. Moreover, of these 14 patients, 12 showed an Al-p level less than 15 units. Al-p level was related to neither the degree of 

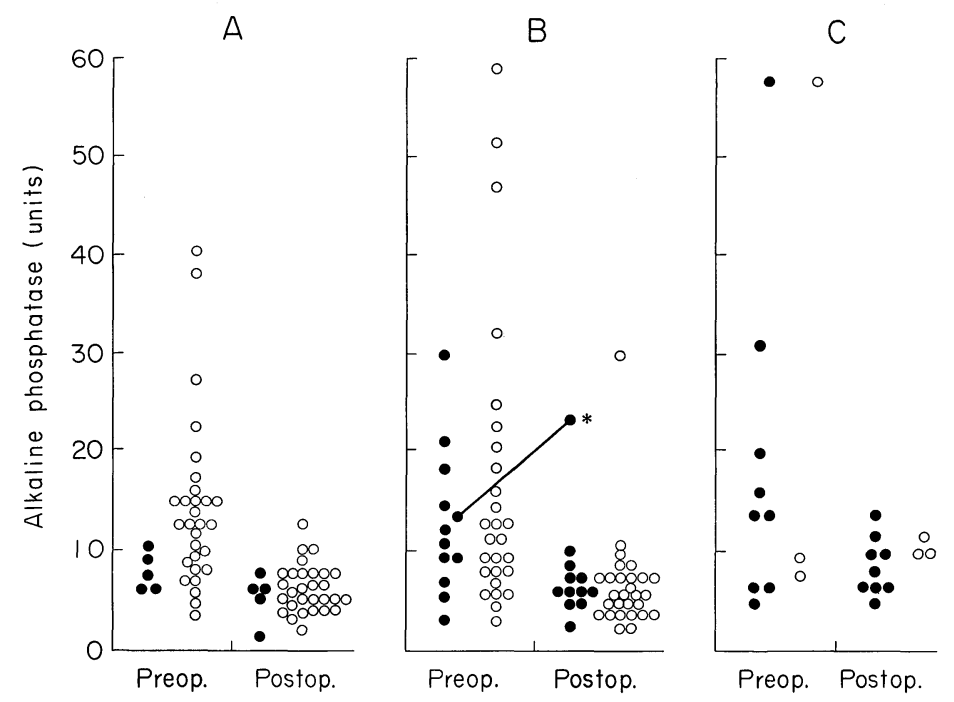

Fig. 1. Changes of Al-p level in relation to the degree of bile-duct dilatation. A: Mildly dilated cases. B: Moderately dilated cases. C: Markedly dilated cases. $\circ$, patients with cholesterol stone; •, patients with calcium bilirubinate stone.

* Patient with recurrent stone.
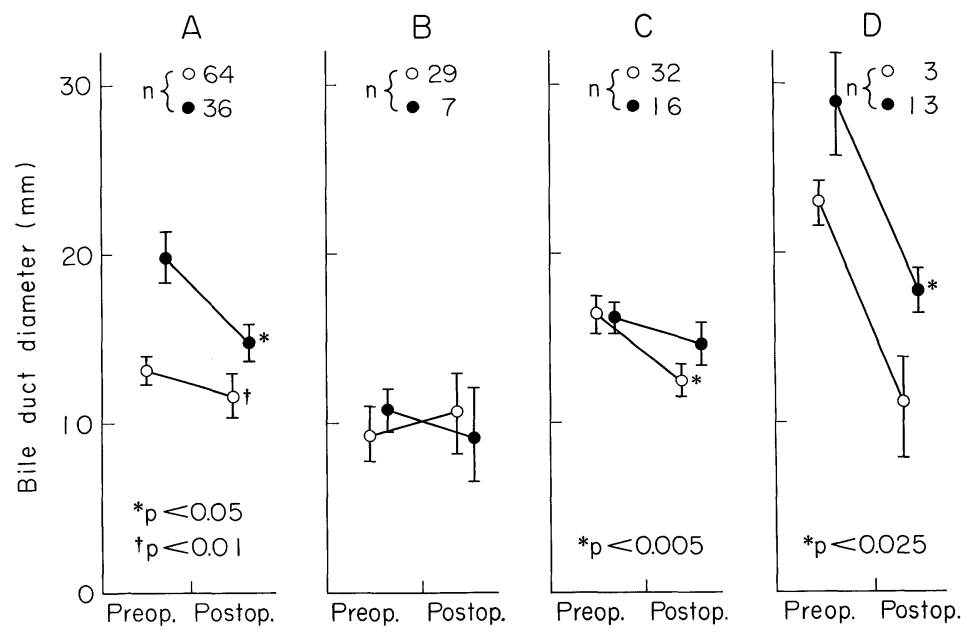

Fig. 2. Changes in diameter of the bile duct at the time of follow-up in relation to the degree of bile-duct dilatation at the time of admission. A: Total cases. B: Mildly dilated cases. C: Moderately dilated cases. D: Markedly dilated cases. O, patients with cholesterol stone; •, patients with calcium bilirubinate stone. Mean \pm s.E.M.

bile-duct dilatation nor the types of gallstone. Abnormal S-GOT level more than 50 units was found in $15.5 \%$ of the patients at the time of discharge and showed no correlation with the types of gallstone or the degree of bile-duct dilatation. At the time of follow-up, however, only $6 \%$ of the patients showed abnormal values of 
S-GOT, more than 50 units but not exceeding 60 units, and again showed no correlation with the types of gallstone or the degree of bile-duct dilatation.

In 100 patients who had undergone preoperative cholangiography, change in a diameter of the bile duct at the time of follow-up was investigated in groups with different types of gallstone and with different degrees of bile-duct dilatation (Fig. 2). In 64 patients with cholesterol stone, preoperative diameter of $13.4 \pm$ $0.5 \mathrm{~mm}$ (mean \pm standard error) was decreased to $11.7 \pm 0.4 \mathrm{~mm}$ at follow-up. In 36 patients with calcium bilirubinate stone, the diameter was also decreased from $19.1 \pm 1.6 \mathrm{~mm}$ to $15.1 \pm 0.8 \mathrm{~mm}$. Changes of the diameter in both groups were statistically significant $(p<0.01, p<0.05)$. The patients with cholesterol stone who had moderate dilatation of the bile duct showed the change of the diameter from $16.6 \pm 0.5 \mathrm{~mm}$ before operation to $12.4 \pm 0.6 \mathrm{~mm}$ at follow-up $(p<0.005)$. Those with calcium bilirubinate stone who had marked dilatation of the bile duct also did so from $29.0 \pm 2.9 \mathrm{~mm}$ to $18.2 \pm 1.1 \mathrm{~mm}(p<0.025)$. The same tendency in reduction of the bile-duct diameter was also recognized in calcium bilirubinate cases with moderate bile-duct dilatation, and cholesterol cases with marked bile-duct dilatation. In patients who previously showed mild dilatation of the bile duct, both the cholesterol and calcium bilirubinate groups tended to show slight reduction in size of the bile duct, at the time of follow-up with no statistically significant difference. Reduction of the bile-duct diameter was distinctively prominent in patients with marked ductal dilatation and surviving more than five years after the operation, regardless of the types of gallstone. There was no correlation between the age of patients and the degree of reduction in size of the bile duct.

Dilatation of the bile duct over the preoperative level at the time of follow-up was found in $19(29.7 \%)$ cholesterol cases and seven $(19.4 \%)$ calcium bilirubinate cases. Increase in diameter, however, was less than $5 \mathrm{~mm}$. Preoperative
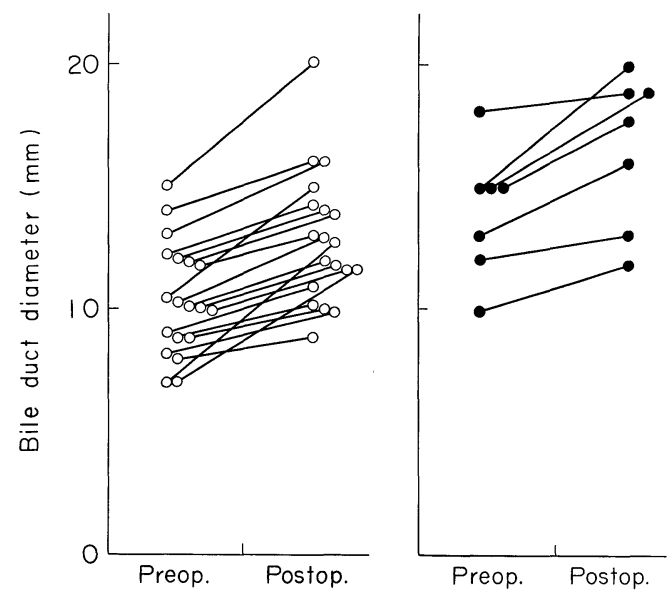

Fig. 3. Patients with enlarged bile duct at the time of follow-up. $\circ$, patients with cholesterol stone; •, patients with calcium bilirubinate stone. 
dilatation of the bile duct in these patients was either mild or moderate, measuring less than $15 \mathrm{~mm}$ (Fig. 3). The questionnaire evaluations of these 26 patients were all "good", and the results of their hepatic function and other tests were all within the normal ranges as well. There was no correlation between the degree of ductal dilatation and postoperative lapse of years in patients who showed ductal dilatation at the time of follow-up.

Studies of "poor" patients at the follow-up. Among the patients who underwent the initial operation at our Department, nine were evaluated as "poor" at follow-up (Table 3). Their diagnoses at the time of initial operation were cholecystocholedocholithiasis in six and choledocholithiasis in three. The types of stone were cholesterol in five and calcium bilirubinate in four patients. Eight out of the nine patients had already been subjected to reoperations at our Department. Cases 4 and 8 were diagnosed to have recurrent gallstones reviewing the previous operative findings, the types of gallstone removed, and cholangiographic study after the initial operation.

TABLE 3. Analysis of patients with "poor" results at the time of follow-up

\begin{tabular}{|c|c|c|c|c|c|c|c|}
\hline \multirow{2}{*}{ No. } & \multirow{2}{*}{$\begin{array}{l}\text { Age } \\
\& \\
\text { sex }\end{array}$} & \multirow{2}{*}{$\begin{array}{l}\text { Location of } \\
\text { stone }\end{array}$} & \multirow{2}{*}{$\begin{array}{l}\text { Degree of } \\
\text { ductal } \\
\text { dilatation }\end{array}$} & \multirow{2}{*}{$\begin{array}{l}\text { Interval } \\
\text { after initial } \\
\text { operation }\end{array}$} & \multicolumn{2}{|c|}{ Types of stone } & \multirow{2}{*}{$\begin{array}{l}\text { Residual } \\
\text { or } \\
\text { recurrent? }\end{array}$} \\
\hline & & & & & $\begin{array}{c}\text { At the initial } \\
\text { operation }\end{array}$ & $\begin{array}{l}\text { At the } \\
\text { reoperation }\end{array}$ & \\
\hline 1 & $53 \mathrm{M}$ & $\begin{array}{c}\text { Gallbladder } \\
\text { bile duct }\end{array}$ & Mild & 2 months & Cholesterol & Cholesterol & Residual \\
\hline 2 & $58 \mathrm{M}$ & $\begin{array}{c}\text { Gallbladder } \\
\text { bile duct }\end{array}$ & Mild & 1 month & Cholesterol & Cholesterol & Residual \\
\hline 3 & $63 \mathrm{M}$ & $\begin{array}{c}\text { Gallbladder } \\
\text { bile duct }\end{array}$ & Mild & 1.8 years & Cholesterol & Cholesterol & Residual \\
\hline 4 & $72 \mathrm{M}$ & $\begin{array}{l}\text { Gallbladder } \\
\text { bile duct }\end{array}$ & Mild & 5.8 years & Cholesterol & $\begin{array}{l}\text { Calcium } \\
\text { bilirubinate }\end{array}$ & Recurrent \\
\hline 5 & $43 \mathrm{~F}$ & Bile duct & Marked & 5 years & $\begin{array}{l}\text { Calcium } \\
\text { bilirubinate }\end{array}$ & $\begin{array}{l}\text { Calcium } \\
\text { bilirubinate }\end{array}$ & Residual \\
\hline 6 & $50 \mathrm{~F}$ & Bile duct & Marked & 10 months & $\begin{array}{l}\text { Calcium } \\
\text { bilirubinate }\end{array}$ & $\begin{array}{l}\text { Calcium } \\
\text { bilirubinate }\end{array}$ & Residual \\
\hline 7 & $67 \mathrm{~F}$ & $\begin{array}{l}\text { Gallbladder } \\
\text { bile duct }\end{array}$ & Moderate & 2.3 years & $\begin{array}{l}\text { Calcium } \\
\text { bilirubinate }\end{array}$ & $\begin{array}{l}\text { Calcium } \\
\text { bilirubinate }\end{array}$ & Residual \\
\hline 8 & $74 \mathrm{M}$ & Bile duct & Moderate & 11 years & $\begin{array}{l}\text { CÉlcium } \\
\text { bilirubinate }\end{array}$ & $\begin{array}{l}\text { Calcium } \\
\text { bilirubinate }\end{array}$ & Recurrent \\
\hline 9 & $49 \mathrm{~F}$ & Bile duct & Moderate & $\begin{array}{l}1.8 \text { years } \\
\text { (under } \\
\text { observation) }\end{array}$ & Cholesterol & & Residual \\
\hline
\end{tabular}

Studies on patients with cholelithiasis who underwent reoperations. Including those who had previously been operated on at other institutions, a total of 134 patients with cholelithiasis underwent reoperations at our Department. They consisted of 65 patients with choledocholithasis, 66 with intrahepatic gallstones, and three with residual stones in the remnant cystic duct. Whether the stones in these patients were residual or recurrent was judged by examining case records, $x$-ray studies before and after operation, operative findings, and the types of gallstone. In consequence, recurrent stone cases counted $11 ; 10$ with choledocholithiasis and one with 
TABLE 4. Incidence of recurrent and residual stones

\begin{tabular}{lccc}
\hline \multirow{2}{*}{ Location of stone } & \multicolumn{3}{c}{ Number of patients } \\
\cline { 2 - 4 } & Recurrent stone & Residual stone & Equivocal \\
\hline Bile duct & 10 & 33 & 22 \\
Intrahepatic duct & 1 & 40 & 25 \\
Remnant cystic duct & 0 & 2 & 1 \\
Total & 11 & 75 & 48 \\
\hline
\end{tabular}

intrahepatic gallstones complicated with congenital choledochal dilatation, while 75 patients were judged as having residual stones and 48 others remained equivocal (Table 4). Therefore, in 86 out of 134 patients who underwent reoperations at our Department, incidences of the residual stone and the recurrent stone were $87.2 \%$ and $12.8 \%$, respectively. The types of stone identified at reoperation were calcium bilirubinate in 10 patients and calcium fatty acid in one. The cause of recurrence could be attributed to bile stasis in all the cases; stricture at the anastomotic site in three, stenosis of the papilla of Vater in two, and postoperative biliary stricture, perivaterian diverticulum and congenital choledochal dilatation in one, respectively. Two patients had stones formed with the silk-thread as cores. The cause of recurrence remained unknown in only two patients who belonged to "poor" at follow-up. The modes of reoperation in these 11 patients were bilioenteric anastomosis in five, sphincteroplasty in two, and choledocholithotomy with T-tube drainage in four. The last four patients showed no apparent stenosis in the papilla of Vater, but in one of them, postoperative examination revealed evidence of perivaterian diverticulum. These four patients are still under observation.

\section{Comments}

In order to permit residual stones to flow away into the intenstinal canal and/or to eliminate bile stasis, transduodenal sphincteroplasty (Stefanini et al. 1974; Jones 1978) and bilioenteric anastomosis (Johnson and Rains 1978; Mudden 1978) are frequently applied as the drainage procedures in the surgical treatment of choledocholithiasis. However, indications of these additional procedures are controversial. The question arises what to do for the patients who have the dilated duct without demonstrable obstruction of the distal common bile duct. To answer this, it is necessary to ascertain whether the dilated bile duct can really become reduced in diameter after the removal of stone with T-tube drainage only, and to grasp the incidence of the recurrence of stone along with its principal causes.

Tsutsumi et al. (1978) reported that, at the time of follow-up, the diameter of the bile duct remained unchanged from the preoperative level in approximately $60 \%$ of the patients with common duct exploration, and recurrent stones were observed in patients whose bile ducts were either unchanged or enlarged. Shimada et al. (1979) noted that among the patients subjected to common duct exploration 
with T-tube drainage, those with the preoperative diameter of the bile duct more than $15 \mathrm{~mm}$ were tended to show conspicuous reduction in size. Those with the diameter more than $25 \mathrm{~mm}$, however, did not demonstrate reduction of diameter to $18 \mathrm{~mm}$ or less at the time of follow-up. In our present series, those subjected to choledocholithotomy with T-tube drainage showed evident reduction in size of the bile duct at the time of follow-up. This was particularly notable in the group of marked bile-duct dilatation. The rate of reduction was not correlated with the types of stone. These results indicate that the bile duct reduces its diameter after choledocholithotomy with T-tube drainage alone. It is conceivable that the indication of sphincteroplasty should not be decided only based upon the existence of bile-duct dilatation.

In addition, to discuss about the indication of the additional procedures for choledocholithiasis, it is necessary to clarify the frequencies of recurrent and residual stones. It is, however, not always easy to decide whether the stones detected at reoperation are recurrent or residual. Since there are no standard criteria for decision, incidences are different in various reports. Ferris et al. (1964) reported that $31(67.4 \%)$ of 46 patients who underwent reoperations were recurrent. In our series of 134 patients subjected to reoperations, $75(87.2 \%)$ had residual stones and $11(12.8 \%)$ had recurrent stones.

In pursuit of causes of recurrent stones, Ferris et al. (1964) classified recurrent stones into "secondary recurrent stones" and "idiopathic recurrent stones". The "secondary recurrent stones" were defined as stones formed as the results of some abnormality in the biliary tract such as benign ductal stenosis, periampullary tumor, or perivaterian diverticulum. The "idiopathic recurrent stones" were defined as stones developed in the biliary tract without any abnormality at the time of reoperation. Saharia et al. (1977) established strict criteria for the diagnosis of "primary common duct stones". Treatment of so called "idiopathic recurrent stones" of Ferris et al. and "primary common duct stones" of Saharai et al. becomes an issue. Of our 11 patients with recurrent stones, nine had the obvious cause such as bile-duct stenosis, and two had unknown causes. Ferris et al. also reported that 15 of 31 patients with recurrent stones were found to have an anatomic alteration which predisposed to the formation of stones. Recurrence of gallstone is considered to be very rare in the absence of abnormality in the bile duct such as ductal stenosis leading to bile stasis.

\section{References}

1) Ferris, D.O., Thomford, N.R. \& Cain, J.C. (1964) Recurrent common bile duct stones. Arch. Surg., 88, 486-489.

2) Johnson, A.G. \& Rains, A.J.H. (1978) Prevention and treatment of recurrent bile duct stones by choledochoduodenostomy. World. J. Surg., 2, 487-496.

3) Jones, S.A. (1978) The prevention and treatment of recurrent bile duct stones by transduodenal sphincteroplasty. World. J. Surg., 2, 473-485.

4) Jones, S.A. \& Smith, L.L. (1952) Transduodenal sphincteroplasty for recurrent pancreatitis. Ann. Surg., 136, 937-947.

5) Jones, S.A., Smith, L.L., Keller, T.B. \& Joergenson, E.J. (1963) Choledochoduo- 
denostomy to prevent resid ual stones. Arch. Surg., 86, 1014-1032.

6) Mudden, J.L. (1978) Primary common bile duct stones. World J. Surg., 2, 465-471.

7) Saharia, P.C., Zuidema, G.D. \& Cameron, J.L. (1977) Primary common duct stones. Ann. Surg., 185, 598-604.

8) Shimada, H., Sato, K., Kito, H., Abe, T., Kure, H., Nagahori, K., Shinmei, K., Kobayashi, M. \& Tsuchiya, S. (1979) Indication of choledochojejunostomy viewed from pathophysiology of choledocholithiasis and intrahepatic lithiasis. Jap. J. Gastroent. Surg., 12 (6), 172. (Japanese)

9) Stefanini, P., Carboni, M., Patrassi, N., De Bernardinis, G., Negro, P. \& Loriga, P. (1974) Transduodenal sphincteroplasty; Its use in the treatment of lithiasis and benign obstruction of the common duct. Amer. J. Surg., 128, 672-677.

10) Tsutsumi, K., Kanno, K., Murayama, Y., Kanazawa, S., Takano, M., Honma, K., Abe, Y., Kawaguchi, H., Tsukada, K., Yoshida, K. \& Muto, T. (1978) Changes of bile duct diameter at the time of follow-up after operation for gallstone and its clinical significance. Jap. J. Gastroente. Surg., 11 (6), 170. (Japanese) 